Erratum

\title{
Erratum to "Total solidification time of a liquid phase change material enclosed in cylindrical/spherical containers" [Applied Thermal Engineering 25 (10) (2005) 1488-1502]
}

Levent Bilir *, Zafer İken

\author{
Department of Mechanical Engineering, İzmir Institute of Technology, Gülbahçe-Urla, 35430, İzmir, Turkey
}

Received 28 April 2005; accepted 30 April 2005

The correct Fig. 4. of the article is as follows:

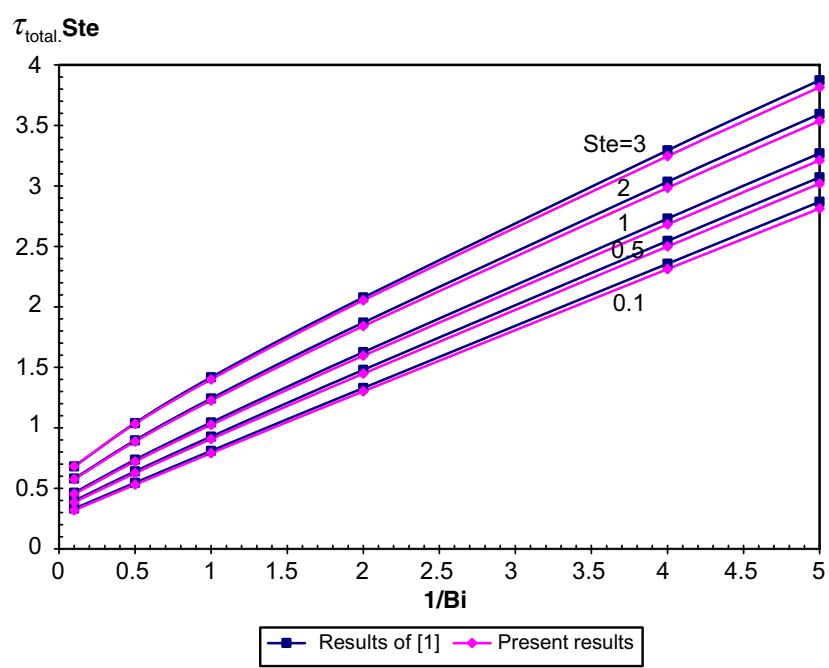

Fig. 4. Comparison of the total solidification time of a cylinder with Ref. [1].

\footnotetext{
DOI of original article: 10.1016/j.applthermaleng.2004.10.005

* Corresponding author. Tel.: +90 232 7506605; fax: +90 2327506505

E-mail address: leventbilir@iyte.edu.tr (L. Bilir).
} 